\title{
THERMAL FATIGUE CRACK GROWTH TESTS AND ANALYSES OF THICK WALL CYLINDER MADE OF MOD.9CR-1MO STEEL
}

\author{
Takashi Wakai $^{1}$, Osamu Inoue ${ }^{2}$, Masanori Ando ${ }^{3}$ and Sumio Kobayashi ${ }^{4}$ \\ ${ }^{1}$ Principal Researcher, Structural Reliability Group, JAEA, Ibaraki, Japan (wakai.takashi@jaea.go.jp). \\ ${ }^{2}$ Manager, IX Knowledge Inc., Tokyo, Japan \\ ${ }^{3}$ Researcher, Structural Reliability Group, JAEA, Ibaraki, Japan \\ ${ }^{4}$ Engineer, Liquid Metal Technology Section, JAEA, Ibaraki, Japan
}

\section{ABSTRACT}

In Japan, the basic designing works for a demonstration plant of Japan Sodium cooled Fast Reactor (JSFR) are now conducted. JSFR is an advanced loop type reactor concept. To enhance the safety and the economic competitiveness, JSFR employs modified $9 \%$ chromium - 1\% molybdenum (Mod.9Cr-1Mo) steel as a material for coolant pipes and components, because the steel has both excellent high temperature strength and thermal properties. The steel has been standardized as a nuclear material in Japan Society of Mechanical Engineers (JSME) code in 2012. In JSFR pipes, demonstration of Leak Before Break (LBB) aspect is strongly expected because the safety assessment may be performed on the premise of leak rate where the LBB aspect is assured. Although the authors have already performed a series of thermal fatigue crack growth tests of austenitic stainless steel cylinders (Wakai et al., 2005), crack growth behavior in the structures made of Mod.9Cr-1Mo steel has not been investigated yet. Especially for the welded joints of Mod.9Cr-1Mo steel, "Type-IV" cracking may occur at Heat Affected Zone (HAZ). Therefore, this study performed a series of thermal fatigue crack growth tests of thick wall cylinders made of Mod.9Cr-1Mo steel including welds, to obtain the crack growth data under cyclic thermal transients. The test results were compared to the analytical results obtained from JAEA's simplified methods (Wakai et al., 2005).

\section{INTRODUCTION}

A number of research works are performed in Japan to establish Sodium cooled Fast Reactors (SFRs) for practical use. According to the present program to develop the Japan Sodium cooled Fast Reactor (JSFR), the first criticality of the demonstration facility for JSFR will be achieved in around 2025 and the commercial plant will be put into the grid in around 2050. To enhance the safety and the economic competitiveness, Japan Atomic Energy Agency (JAEA) proposes an attractive plant concept and makes many efforts to demonstrate the applicability of some innovative technologies to the plant. One of the most practical means to enhance the economic competitiveness is to reduce the construction costs by diminishing the total amount of structural materials. To meet the requirements, high-Cr ferritic steel has attractive characteristics as a main structural material of SFRs, because the steel has both excellent thermal properties and high temperature strength. Employing the steel as the main structural material, remarkable compact plant design can be achieved as shown in Fig.1. For the demonstration facilities for JSFR, modified 9\% chromium - 1\% molybdenum (Mod.9Cr-1Mo) steel is employed as the main structural material, because the steel has already been standardized in the ASME code and used in many thermal power boilers.

In SFRs, if the coolant pipe ruptures and large amounts of coolant sodium leaks, it may be difficult to maintain the necessary coolant level in the reactor vessel, because it is impossible to inject the coolant into the reactor core. In addition, according to the present in-service inspection (ISI) program for 
JSFR, continuous leak monitoring substitutes for volumetric tests on the basis of ensuring the Leak Before Break (LBB) aspect. Therefore, it is required that the LBB aspect must be demonstrated in the JSFR sodium pipes. For austenitic stainless steel pipes, a LBB assessment procedure has been proposed (afcen, 2010), but the procedure for Mod.9Cr-1Mo steel pipes has not been investigated yet. Generally speaking, ductility and toughness of Mod.9Cr-1Mo steels are relatively inferior to those of austenitic stainless steels. The SFR pipes have very thin wall thickness, therefore, the stiffness is relatively small. In addition, since displacement controlled thermal expansion stress is predominant in the SFR pipes, the stiffness decreases and stress at the crack portion decreases with crack extension. To establish the LBB assessment procedures for the Mod.9Cr-1Mo steel pipes in the SFRs, both such material and structural features must be taken into account. The authors have proposed a LBB assessment flowchart (Wakai et al., 2010). However, crack growth assessment method for Mod.9Cr-1Mo steel has not proposed yet. Thus, this paper studies the applicability of a simplified crack growth assessment method proposed by JAEA (Wakai et al., 2005) to Mod.9Cr-1Mo steel structure. The method had been validated using thermal fatigue crack growth test results for a thick wall cylinder made of type 304 austenitic stainless steel containing complete circumference initial notches. However, the applicability of the method to the assessment of semi-elliptical shape notches and notches in the weld metals and/or Heat Affected Zone (HAZ) has not been verified yet. Therefore, this paper verifies the validity of the method using the thermal fatigue crack growth assessment method for axial and circumferential semi-elliptical notches in weld metal and HAZ as well.
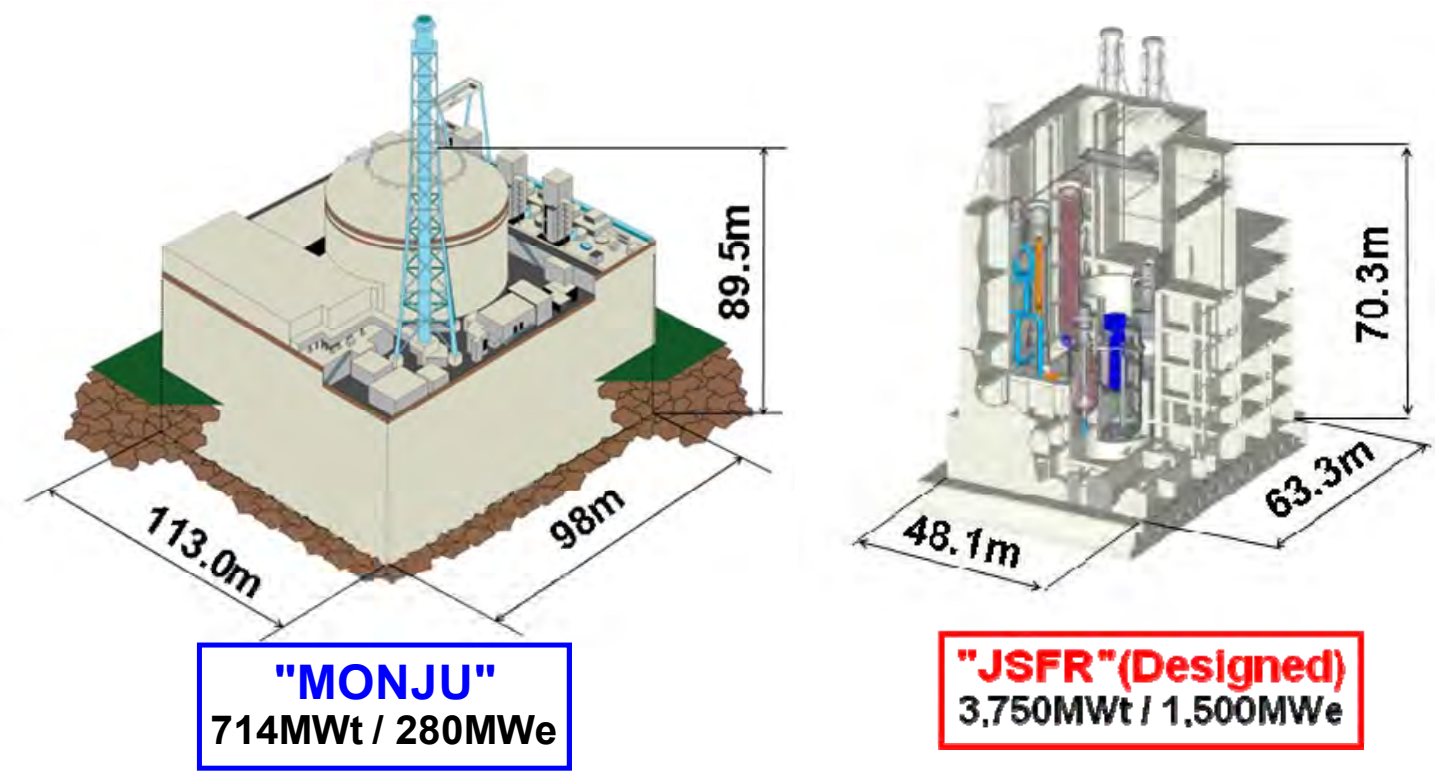

Figure 1 Compact plant design achieved by employing some innovative technologies

\section{EXPERIMENTS}

\section{Test facility and specimens}

Presently, 2 thermal fatigue crack growth tests using thick wall cylinders made of Mod.9Cr-1Mo steel were completed, using "Air-cooled Thermal Transient test Facility (ATTF)". The external appearance of the facility is shown in Fig.2 (a).

Figure 2 (b) shows the experimental apparatus in ATTF. The thickness of the cylinder was $40 \mathrm{~mm}$ and 3 semi elliptical initial defects were machined on the inner surface. The first test was 
conducted to obtain the crack growth data for axial cracks and the second one was for circumferential cracks. Both axial and circumferential initial defects have 3.0mm depth and $30.0 \mathrm{~mm}$ length. One was machined at base material region and the others were machined at weld metal and HAZ, respectively, as shown in Fig.3.

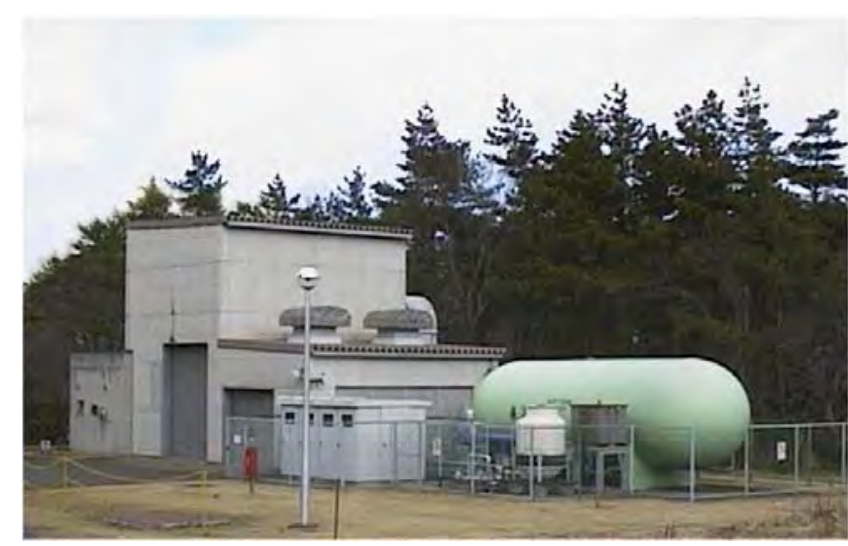

(a) External appearance of ATTF

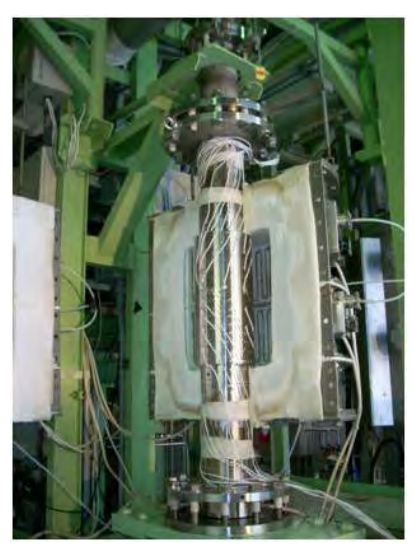

(b) Specimen mounted on the facility

Figure 2 Photographs of test facility and specimen

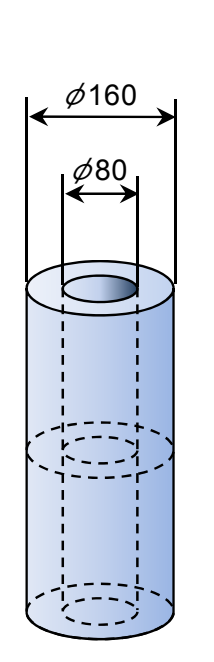

(a) Cylinder

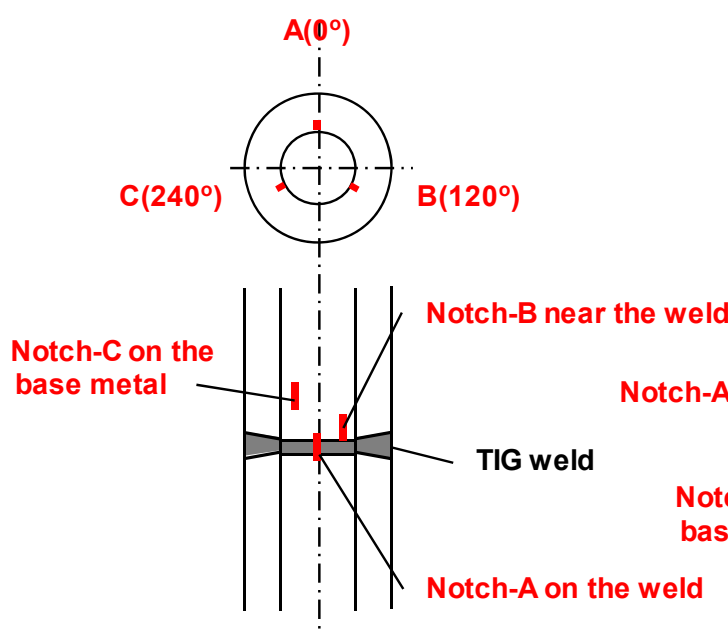

(b) Axial notches
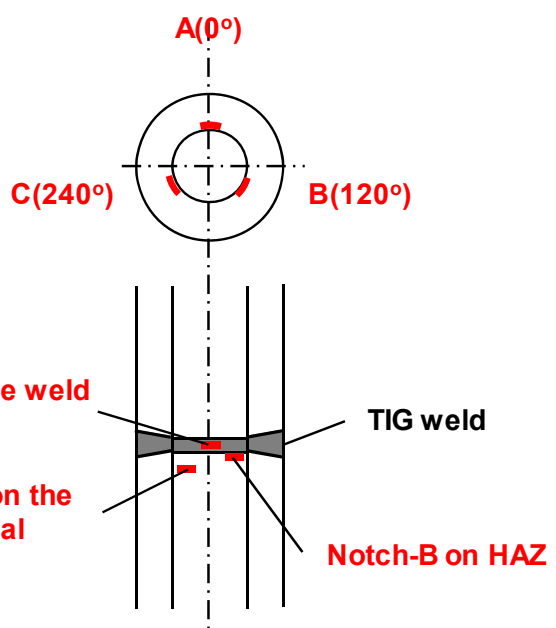

(c) Circumferential notches

Figure 3 Shape and dimensions of the specimen

\section{Thermal transient conditions}

The inner surface of the cylinder was subjected to cyclic thermal shocks by pressurized air. Figure 4 shows the temperature history. The most severe temperature gradient arose at $60 \mathrm{sec}$, approximately. To obtain the stress distribution across the wall thickness, thermo-elastic finite element analysis (FEA) was conducted by using a general-purpose non-linear structure analysis system - FINAS (JAEA (2008)). 

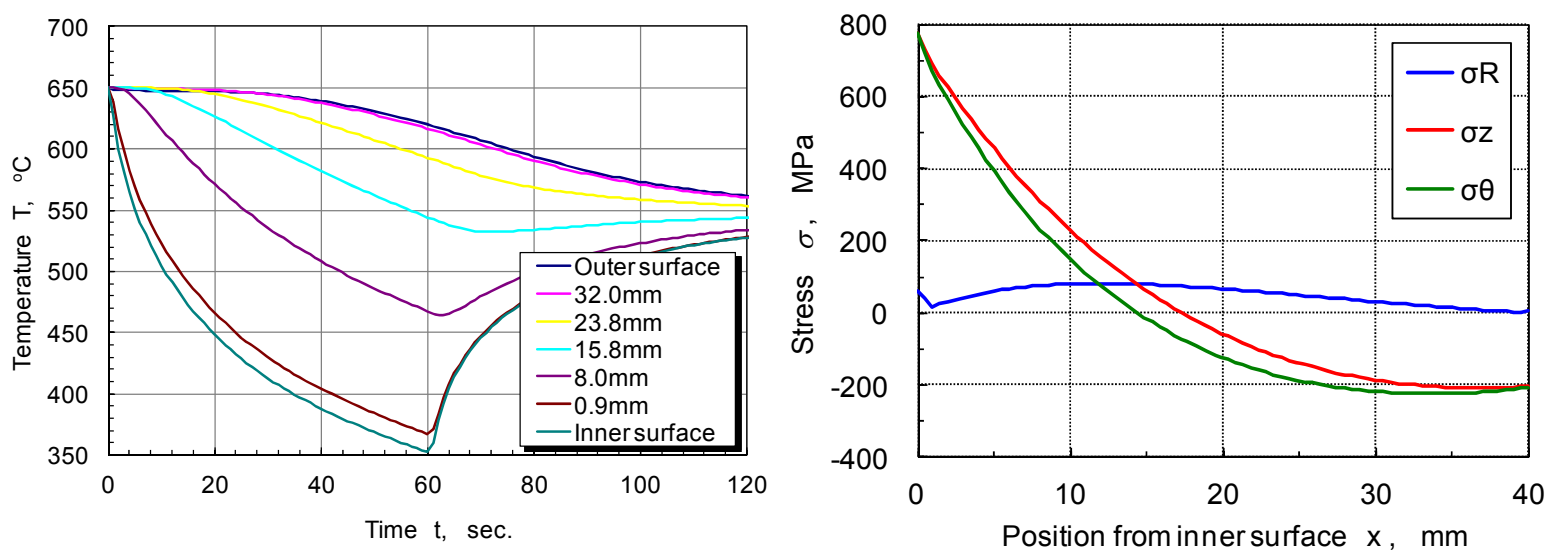

Figure 4 Temperature history

Figure 5 Radial, axial and hoop stress distribution

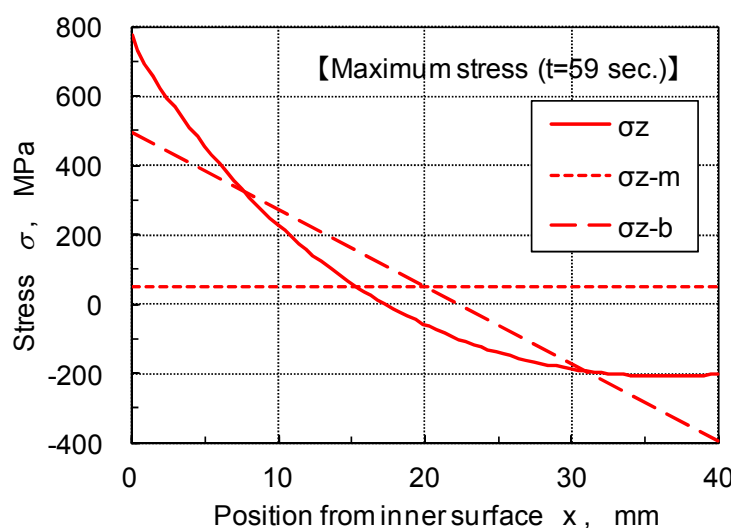

(a) Axial stress

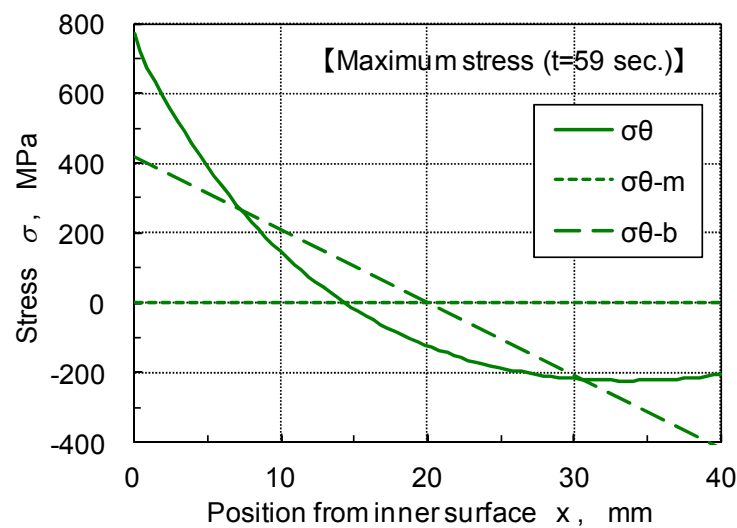

(b) Hoop stress

Figure 6 Membrane, bending and parabolic stress components

\section{SIMPLIFIED CRAK GROWTH ASSESSMENT METHOD}

The fatigue crack growth rate is calculated as a function of J-integral range as follows ;

$$
\frac{d a}{d N}=C_{f} \cdot(\Delta J)^{m_{f}}
$$

Above equation is well known as Paris law, where $C_{f}$ and $m_{f}$ is material constants. In this study, the calculation of J-integral range takes elastoplastic deformation into account.

Using the influence function method based on the principle of superposition, the following stress intensity factor solution is calculated ;

$$
K_{e q}=\left(F_{m} \sigma_{m}+F_{b} \sigma_{b}+F_{p} \sigma_{p}\right) \sqrt{\pi a}
$$

where $F_{m}, F_{b}$ and $F_{p}$ are non-dimensional factors for membrane, bending and parabolic stresses, respectively. $a$ is the crack size. Non-dimensional stress intensity factor solutions have to be chosen suitable for the structural conditions, such as geometry, location and so on. In this study, Raju-Newman's 
solutions (Raju et al. (1982)) were used for the axial crack and Shiratori's solutions (Shiratori et al. (1990)) were used for the circumferential crack.

In eqn.(2), $\sigma_{\mathrm{m}}$ and $\sigma_{\mathrm{b}}$ are the elastoplastic membrane and bending stresses accounting for plasticity. $\sigma_{p}$ is determined from the elastic membrane and bending stresses, $S_{m}$ and $S_{b}$, respectively, and the non-linear stress distribution through the wall thickness. $S_{m}, S_{b}$ and $S_{p}$, the parabolic stress component, are defined as shown in Fig.7. The stress distribution is obtained from a thermo-mechanical FEA.

The membrane stress $\sigma_{\mathrm{m}}$ is obtained using the cyclic stress-strain curve of the material and a parameter $\mathrm{q}_{\mathrm{ep}}$ as shown in Fig.8. For the bending stress, $\left(\sigma_{\mathrm{m}+\mathrm{b}}, \sigma_{\mathrm{m}+\mathrm{b}}\right)$ and $\left(\sigma_{\mathrm{m}-\mathrm{b}}, \sigma_{\mathrm{m}-\mathrm{b}}\right)$ are determined using the cyclic stress-strain curve of the material and a parameter qep, as illustrated in Fig.9(a). The resulting elastoplastic stress distribution through the wall thickness is shown in Fig.9(b). The elastoplastic bending stress $\sigma_{\mathrm{b}}$ is then calculated from the equivalent bending moment $\mathrm{M}_{\mathrm{eq}}$.

In this benchmark, since it can be assumed that the tests were carried out at $\mathrm{R}=0$, the elastic $\mathrm{J}$ integral range $\Delta \mathrm{J}_{\mathrm{el}}$ is calculated by :

$$
\Delta J_{e l}=\frac{K_{\max }^{2}}{E^{*}}
$$

where Kmax is the maximum stress intensity factor in the loading cycle. $E^{*}=E /\left(1-v^{2}\right)$ for this benchmark, since plain strain condition can be assumed. The elastoplastic J-integral range $\Delta \mathrm{J}_{\mathrm{ep}}$ is obtained from $\Delta \mathrm{J}_{\mathrm{el}}$ using a plastic correction factor $\mathrm{f}_{\mathrm{ep}}$ based on R6 method (Ainsworth et al. (1984)) :

and

$$
\Delta J_{e p}=f_{e p} \cdot \Delta J_{e l}
$$

$$
f_{e p}=\frac{\sigma_{r e f}{ }^{3}}{2 \sigma_{y}{ }^{2} \cdot E \cdot \varepsilon_{\text {ref }}}+\frac{E \cdot \varepsilon_{r e f}}{\sigma_{r e f}}
$$

where $\sigma_{\text {ref }}$ is the reference stress calculated at the maximum load of the cycle, $\varepsilon_{\text {ref }}$ is the corresponding reference strain and $\sigma_{\mathrm{y}}$ is the $0.2 \%$ proof stress derived from the cyclic stress-strain curve of the material. The reference stress is determined using a net section shape function $F_{\text {net }}$ :

$$
\sigma_{\text {ref }}=F_{\text {net }}\left(p_{m} \cdot \sigma_{m}+p_{b} \cdot \sigma_{b}\right)
$$

In the thermal fatigue tests, since it can be assumed that there is no primary stress, $F_{\text {net }}$ is given as a constant that depends upon the nature of the loads. For the thick wall cylinder, it is assumed that the thermal transient produces almost pure bending loads. Therefore, $F_{\text {net }}$ is assumed to be 2/3. For the sake of simplicity, curvature of the pipe due to the nature of the loads was neglected. The values of $\mathrm{p}_{\mathrm{m}}$ and $\mathrm{p}_{\mathrm{b}}$ are recommended $\mathrm{p}_{\mathrm{m}}=\mathrm{p}_{\mathrm{b}}=1.0$. 


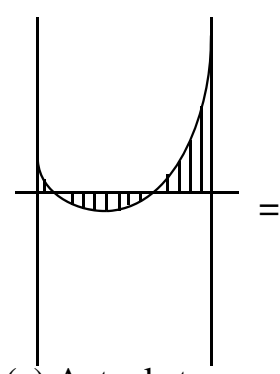

(a) Actual stress distribution

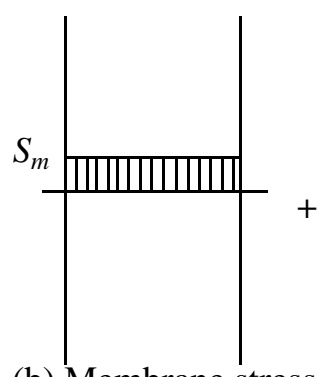

(b) Membrane stress

(c) Bending stress

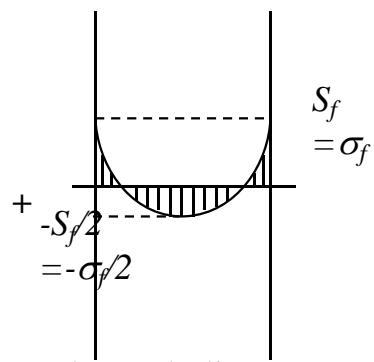

(d) Parabolic stress

(Thermo-mecanical FEA)

Figure 7 Membrane, bending and parabolic stresses used in the analysis
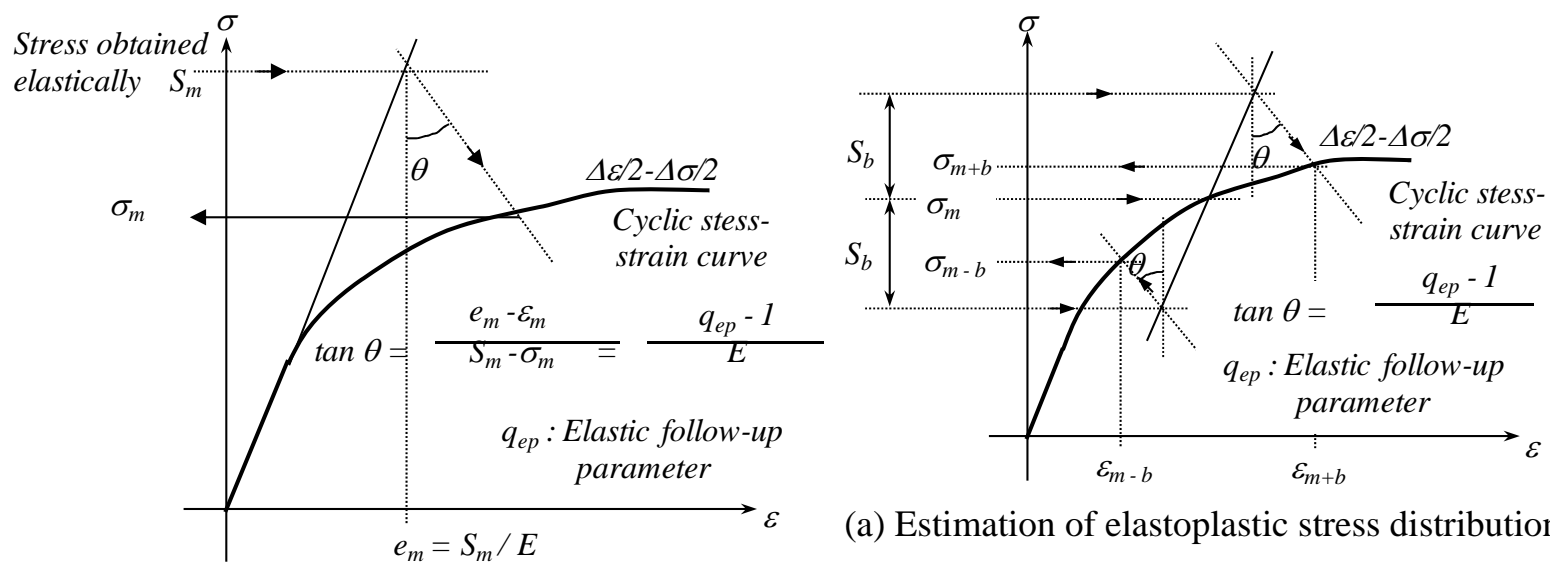

(a) Estimation of elastoplastic stress distribution

Figure 8 Determination of $\sigma_{\mathrm{m}}$ in the analysis

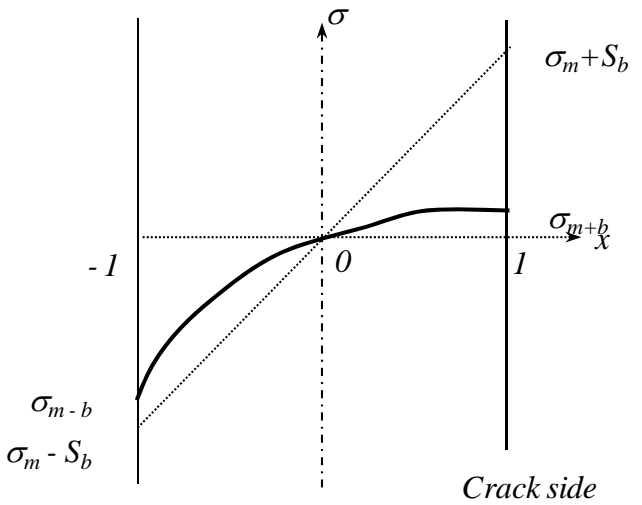

(b) Elastoplastic stress distribution

Figure 9 Determination of $\sigma_{\mathrm{b}}$ in the analysis

\section{FATIGUE CRACK GROWTH TESTS FOR THE MATERIAL}

A series of fatigue crack growth tests was conducted at elevated temperature for modified 9Cr1 Mo steel base metals (BM) and welded joints. The fatigue crack growth tests were carried out using compact tension (CT) specimens with $12.7 \mathrm{~mm}$ in thickness. Shape and dimension of the CT specimens 
are shown in Fig.10. For the weld joints, the notch was machined at HAZ. Prior to the crack growth tests, high-cycle fatigue pre-cracking were introduced in accordance with ASTM E647-05 (ASTM, 2005). Side grooves were machined on both sides after the high-cycle fatigue pre-cracking process to avoid a "tunneling” of crack.

Figure 11 shows the results of fatigue crack growth tests. Based on these results, coefficient, $\mathrm{C}_{\mathrm{f}}$, and exponent, $\mathrm{m}_{\mathrm{f}}$, of Paris law given by eq.(1) were determined as follows.

$$
\begin{aligned}
& \text { For Base Metal : } \quad \mathrm{C}_{\mathrm{f}}=3.056 \times 10^{-5}, \quad \mathrm{~m}_{\mathrm{f}}=1.310 \\
& \text { For HAZ } \quad: \quad \mathrm{C}_{\mathrm{f}}=3.721 \times 10^{-5}, \quad \mathrm{~m}_{\mathrm{f}}=1.310
\end{aligned}
$$

As you can see, the exponents for Base Metal and HAZ are almost same.

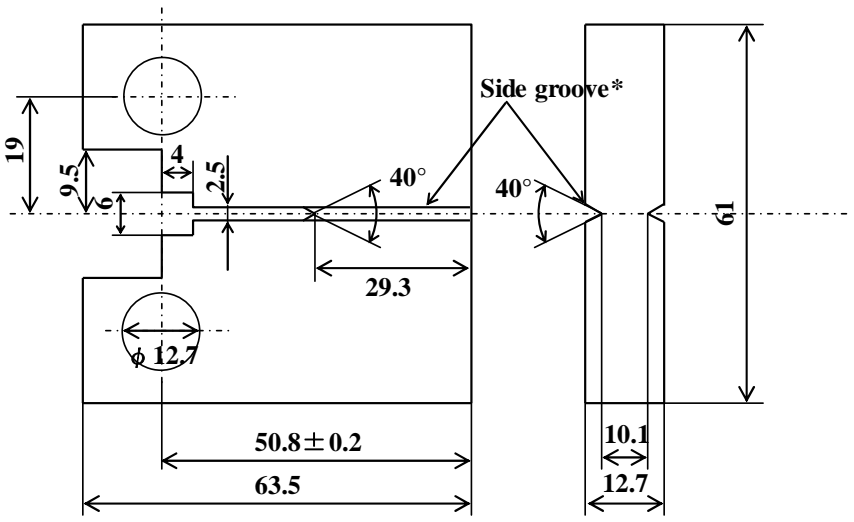

Figure 10 Shape and dimensions of fatigue crack growth test specimen

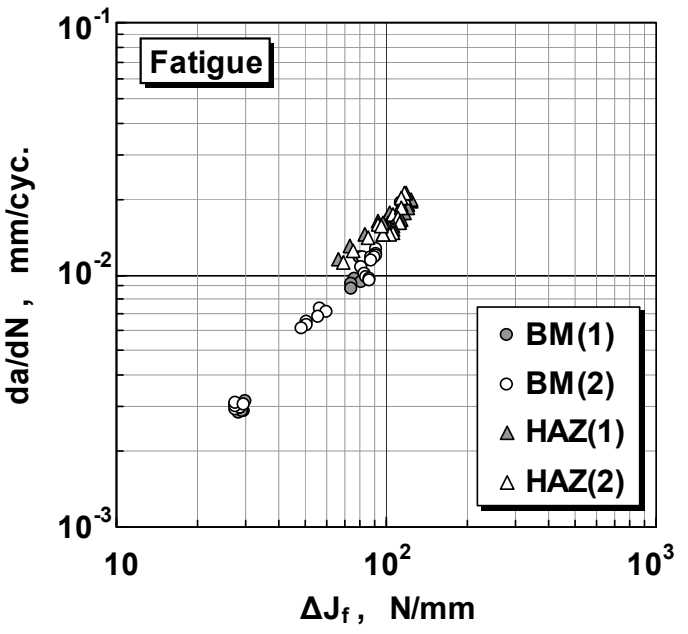

Figure 11 Results of fatigue crack growth tests

\section{COMPARISON BETWEEN EXPERIMENTAL AND ANALYTICAL RESULTS}

Calculation results were compared with the observations. Figure 12 shows the comparison of experimental and analytical crack growth behavior. In Fig.12 (a) and (b), axial crack growth behaviors are shown. As shown in Fig.12(a), the calculation results to the depth direction are in a good agreement with the observations. In contrast, slightly small crack growth rates are predicted to the length direction, as shown in Fig.12(b). Figure 12 (c) and (d) show the circumferential crack growth behaviors. The calculation method well predicted the crack growth to the depth direction, except the case where the initial notch was machined at HAZ, as shown in Fig.12(c). Similarly to the axial crack cases, the calculation method provided small crack growth rate to the length direction, as shown in Fig.12(d).

Figure 13 shows the pictures of the inner surface of the specimens after the penetration tests. In both specimens, a number of random small surface cracks were observed. It is supposed that such surface cracks initiated due to the non-linear peak temperature distribution near the inner surface at the beginning of thermal transients. These surface cracks were connected to the main cracks propagated from the machined defects. In the destructive tests, it was very difficult to identify the main crack propagation from the connection with the initiated small surface cracks. The discrepancies observed in Fig.12(b) and (d) were caused by the difficulty in the distinguish between the main crack propagations and small cracks initiated in the test. 


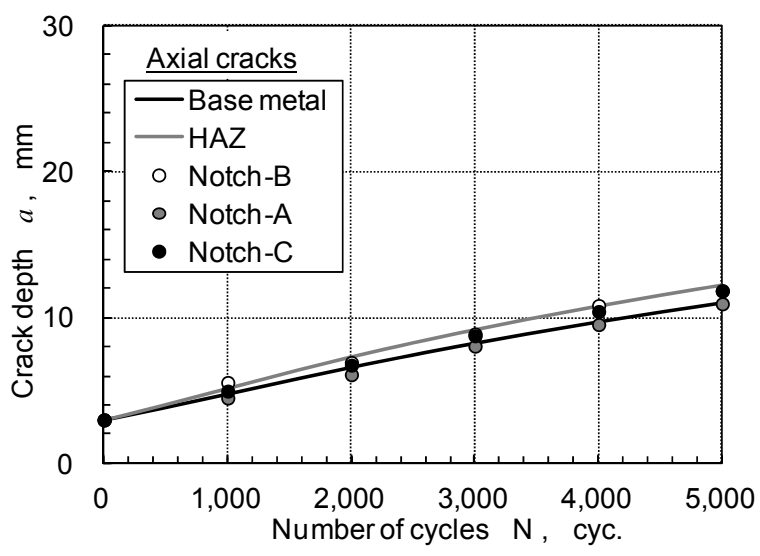

(a) Axial crack growth to depth direction

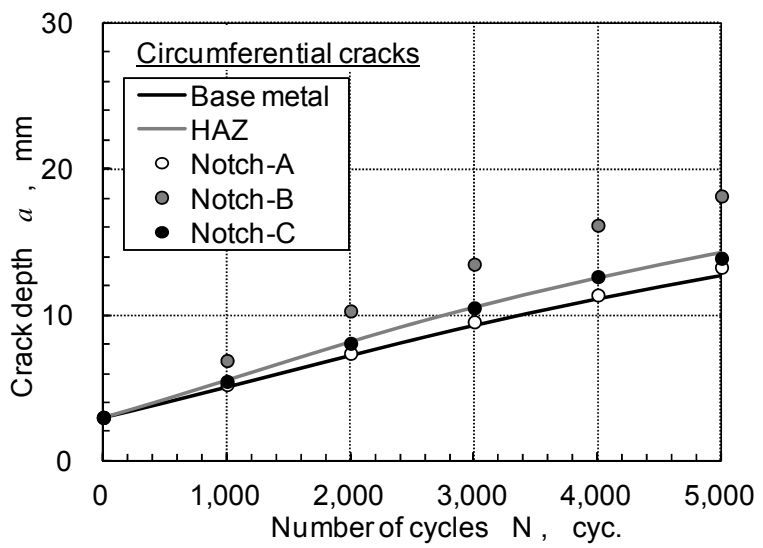

(c) Circumferential crack growth to depth direction

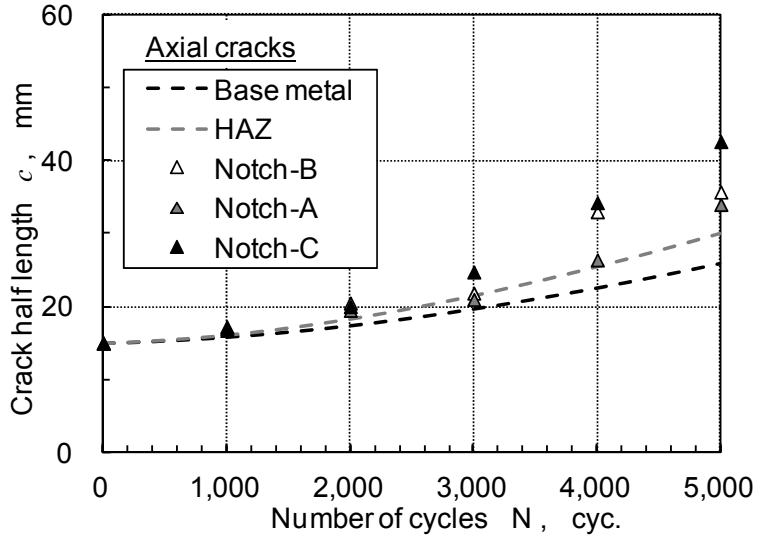

(b) Axial crack growth to surface direction

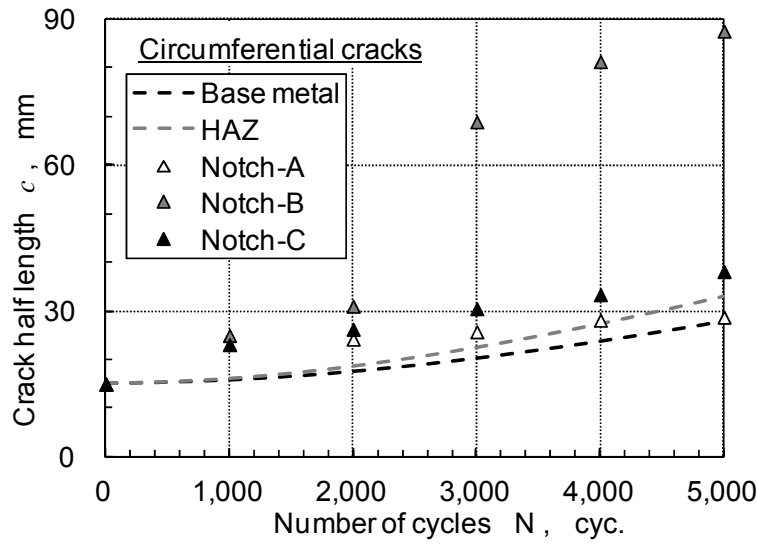

(d) Circumferential crack growth to surface direction

Figure 12 Comparison between analytical and experimental results

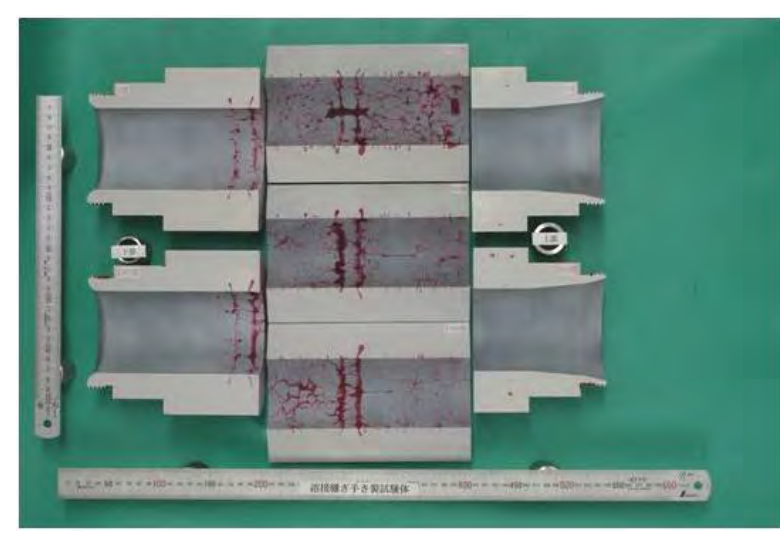

(a) Specimen containing axial cracks

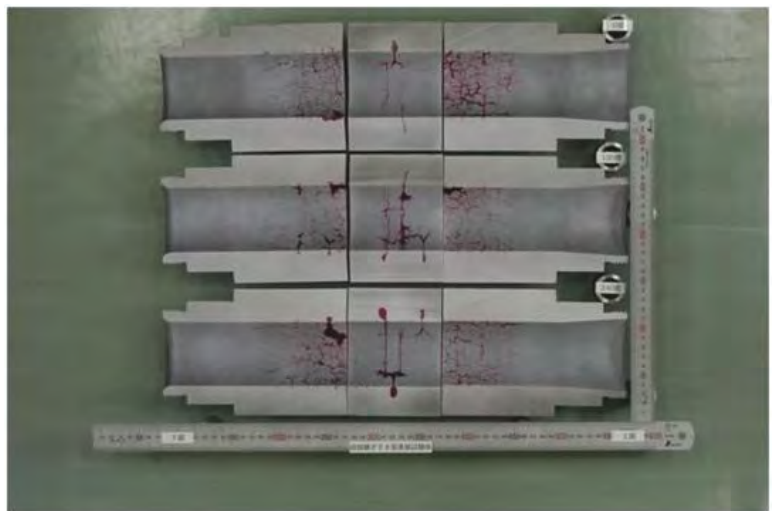

(b) Specimen containing circumferential cracks

Figure 13 Inner surface observation after the completion of the tests 


\section{CONCLUSIONS}

Crack growth data were collected for axial and circumferential semi-elliptical cracks at base metal, weld metal and HAZ from Mod.9Cr-1Mo steel cylinders subjected to cyclic thermal transients. Numerical analyses were also performed for the test conditions and analytical results were compared with the observations. It was demonstrated that a simplified crack growth assessment methods could predict the crack growth behaviors. The methods may be able to adopt to the LBB assessment of JSFR pipes made of Mod.9Cr-1Mo steel.

\section{REFERENCES}

Raju, I. S., Newman, J. C. Jr., "Stress Intensity Factors for Internal and External Surface Cracks in Cylindrical Vessels”, Journal of Pressure Vessel technology, Vol.104, No.11, pp293-298 (1982).

Ainsworth, R.A. et al., The Assessment of Defects in Structures of Strain Hardening Material, Engineering Fracture Mechanics, Vol.19 (1984), No 4, pp.633-642.

Shiratori, M., “Analyses of Stress Intensity Factors by Influence Function Method”, Material for JSME seminar, in JAPANESE (1990).

Japan Atomic Energy Agency \& ITOCHU Techno-Solutions Corporation, "FINAS Ver.19 User's Manual”, (2008).

Wakai, T., Horikiri, M., Poussard, C., Drubay, B. (2005), “A comparison between Japanese and French A16 defect assessment procedures for thermal fatigue crack growth, Nuclear Engineering and Design”, Vol.235, No.9, pp.937-944.

ASTM, E647-05 “Standard Test Method for Measurement of Fatigue Crack Growth Rates”, (2005).

afcen, "RCC-MRx Section III - Tome 1 - Subsection Z - Appendix A16: Guide for Prevention of Fast Fracture, Leak Before Break Analysis and Defect Assessment”, (2010). 